\title{
セラミックスに対する確率論的等疲労寿命線図*
}

\section{Probabilistic Constant Fatigue Life Diagrams for Ceramics} \\ Shinya MATSUDA*1 and Keiji OGI \\ ${ }^{* 1}$ Numazu National College of Technology, Department of Mechanical Engineering \\ Ooka 3600, Numazu-shi, Shizuoka, 410-8501 Japan
}

松田 伸也*1

This paper presents a probabilistic model for predicting the constant fatigue life (CFL) diagrams for ceramics. First, a unified probabilistic delayed-fracture (PDF) model was proposed on the basis of the slow crack growth (SCG) concept in conjunction with the two-parameter Weibull distribution. Second, probabilistic CFL diagrams for effective volume $V_{\text {eff }}$, effective loading time $t_{\text {eff }} N_{\mathrm{f}}$, fracture probability $F$ and stress ratio $R$ were obtained using the PDF model. The probabilistic CFL diagram was then related with the modified Goodman's diagram. Third, the unified strength parameters associated with the PDF model were determined using the experiment data of $\mathrm{Si}_{3} \mathrm{~N}_{4}$ subjected to rotating bending. The stress amplitude - the number of cycles to failure curves were then predicted for $R=-1$ and 0 and various values of $F$. Moreover, the probabilistic CFL diagrams for various values of $V_{\text {eff }}$ and $t_{\text {eff }} N_{\mathrm{f}}$ at $F$ were depicted using the unified strength parameters. The validity of the present model was confirmed through the comparison of the predicted CFL diagrams with the experiment data.

Key Words : Ceramics, Cyclic Fatigue Strength, Stress Ratio Dependence, Constant Fatigue Life Diagram, Slow Crack Growth, Probabilistic Methods

\section{1. 緒言}

ちつ化ケイ素 $\left(\mathrm{Si}_{3} \mathrm{~N}_{4}\right)$ や炭化ケイ素（ $\mathrm{SiC} ）$ のような工業用ファインセラミックス材料は今日の様々な構造部 材や電子デバイスとして幅広く適用されている．たとえば， $\mathrm{Si}_{3} \mathrm{~N}_{4}$ は耐摩耗性や高比強度を有するため，コモンレ ールシステムの逆止弁(1)やベアリング用ボール(2)として適用されている。一方 $\mathrm{SiC}$ は, 低密度, 高剛性, 高硬度, 高熱伝導率を有し，耐熱性，化学的安定性に優れているため，半導体基板としても使用されている．さらに核融 合炉構造や航空宇宙分野におけるミラーデバイスへの適用が期待されている．また近年，構造部材に適用するた めに高強度反応焼結 $\mathrm{SiC}$ と呼ばれる新しい材料が開発されている(3)(4). このようなセラミックスの適用の増加に伴 い，これら部材の長期信頼性確保のために損傷や破壊の観点から，繰返し負荷下でのセラミックスの強度や寿命 を評価することが重要である.

様々なサイズの欠陥を多数有しているセラミックスにおいて，安定き裂成長（Slow crack growth；SCG）はよく 知られており, 一般的に, き裂先端での応力拡大係数 $K_{\mathrm{I}}$ を用いたべき乗則 (SCG 則) で表現される(5)(6). これは, 脆いセラミックス中のき裂進展に対して最大応力 $\sigma_{\max }$ や応力保持時間の効果が大きく, 金属材料でみられるよ うな応力振幅 $\sigma_{\mathrm{a}}$ や平均応力 $\sigma_{\mathrm{m}}$, 応力比 $R$ の影響が比較的小さいためである.

セラミックスの損傷に関するよく知られた研究として, Evans らは様々な荷重下での損傷過程や SCG 理論に基 づく損傷予測のための基礎的解析手法を論じている ${ }^{(5)}$ (10). この理論に基づき，種々のセラミックスを用いた様々 な破壊試験を通して, S- $\dot{\sigma}$ （ $\dot{\sigma}$ : 応力速度）線図，S-N 線図および S-t 線図の予測や SCG パラメータの評価が行

* 原稿受付 2012 年 1 月 16 日

*1 正員, 沼津工業高等専門学校機械工学科（广410-8501 静岡県沼津市大岡 3600）

*2 正員, 愛媛大学大学院理工学研究科生産環境工学専攻

E-mail: matsuda@numazu-ct.ac.jp 
われてきた ${ }^{(11) \sim(15)}$. またそれら線図の確率論的予測や構造物のための信頼性設計手法は, SCG 概念とワイブル分 布を組み合わせた確率論的モデルによって論じられてきた ${ }^{(16)(19)}$.一方, 室温または高温下での疲労強度に及ぼす $R$ 依存性は主に等疲労寿命（Constant fatigue life, 以下 CFL) 線図によって評価されている(20) (22). CFL 線図は, 金属材料のための設計基準である後述の実験式を用いて表されるが，理論的根拠は明確とは言えない．

そこで本論文では，セラミックスの CFL 線図を予測するための確率論的モデルを構築した．初めに，SCG 則 と不活性強度の 2 母数ワイブル分布を組み合わせた確率論的遅れ破壊（Probabilistic delayed-fracture，以下 PDF） モデルを提案し, 有効体積 $V_{\mathrm{eff}}$, 有効負荷時間 $t_{\mathrm{eff}} N_{\mathrm{f}}$ および破壊確率 $F$ に対する確率論的 CFL 線図を得た. 次 に, 回転曲げを受ける $\mathrm{Si}_{3} \mathrm{~N}_{4}$ の実験データと確率論的 CFL 線図の予測結果を比較することにより，モデルの妥当 性を検証した.

\section{2. モデリング}

\section{$2 \cdot 1$ 実験的 CFL 線図}

これまでに，金属材料の疲労限度の $R$ 依存性を説明寸る様々な実験的関係が提案されてきた. これらの定式化 は Marin ${ }^{(23)} の 一$ 般的な式に集約される :

$$
\left(\frac{\sigma_{\mathrm{a}}}{\sigma_{\mathrm{w}}}\right)^{\alpha}+\left(f \frac{\sigma_{\mathrm{m}}}{\sigma_{\mathrm{B}}}\right)^{\beta}=1
$$

ここで, $\sigma_{\mathrm{a}}, \sigma_{\mathrm{m}}, \sigma_{\mathrm{w}}$ および $\sigma_{\mathrm{B}}$ はそれぞれ応力振幅, 平均応力, $\sigma_{\mathrm{m}}=0$ での疲労限度, 引張強度であり, $\alpha, \beta$ および $f$ は材料定数である. また $\sigma_{\mathrm{a}}$ と $\sigma_{\mathrm{m}}$ は， $\sigma_{\max }$ と $R$ を用いて次のように与えられる：

$$
\begin{aligned}
& \sigma_{\mathrm{a}}=\frac{1-R}{2} \sigma_{\max } \\
& \sigma_{\mathrm{m}}=\frac{1+R}{2} \sigma_{\max }
\end{aligned}
$$

式（1）は $\alpha, \beta$ および $f$ の值によって以下のような実験式に変換される：

- $\alpha=1, \beta=1$ および $f=\sigma_{\mathrm{B}} / \sigma_{\mathrm{Y}}\left(\sigma_{\mathrm{Y}}\right.$ : 降伏灾力 $)$ のとき, Soderberg 線図 :

$$
\frac{\sigma_{\mathrm{a}}}{\sigma_{\mathrm{w}}}+\frac{\sigma_{\mathrm{m}}}{\sigma_{\mathrm{Y}}}=1
$$

- $\alpha=1, \quad \beta=1$ および $f=1$ のとき, 修正 Goodman 線図 :

$$
\frac{\sigma_{\mathrm{a}}}{\sigma_{\mathrm{w}}}+\frac{\sigma_{\mathrm{m}}}{\sigma_{\mathrm{B}}}=1
$$

- $\alpha=1, \quad \beta=2$ および $f=1$ のとき, Gerber 線図 :

$$
\frac{\sigma_{\mathrm{a}}}{\sigma_{\mathrm{w}}}+\left(\frac{\sigma_{\mathrm{m}}}{\sigma_{\mathrm{B}}}\right)^{2}=1
$$

- $\alpha=2, \quad \beta=1$ および $f=1$ のとき, Dietman 線図 :

$$
\left(\frac{\sigma_{a}}{\sigma_{w}}\right)^{2}+\frac{\sigma_{m}}{\sigma_{B}}=1
$$

- $\alpha=2, \quad \beta=2$ および $f=1$ のとき, Elliptical 線図 : 


$$
\left(\frac{\sigma_{\mathrm{a}}}{\sigma_{\mathrm{w}}}\right)^{2}+\left(\frac{\sigma_{\mathrm{m}}}{\sigma_{\mathrm{B}}}\right)^{2}=1
$$

式 (3) 〜 (7) 中の $\sigma_{\mathrm{w}}$ を与えられた疲労寿命 $N_{\mathrm{f}}$ に対する疲労強度 $\sigma_{\mathrm{w}}\left(N_{\mathrm{f}}\right)$ に置き換えることにより， $N_{\mathrm{f}}$ での $\sigma_{\mathrm{a}}-\sigma_{\mathrm{m}}$ 線図が得られるため, これらは実験的 CFL 線図と呼ぶことができる. 特に式 (4) の修正 Goodman 線図 は，室温でのセラミックスの疲労強度の $R$ 依存性を上手く説明できる(21)(22).

一方，式（1）において $\alpha=\beta=\gamma ， \sigma_{\mathrm{w}}=\sigma_{\mathrm{w}}\left(N_{\mathrm{f}}\right)$ および $f=1$ とおくと，次式が得られる：

$$
\left(\frac{\sigma_{\mathrm{a}}}{\sigma_{\mathrm{w}}\left(N_{\mathrm{f}}\right)}\right)^{\gamma}+\left(\frac{\sigma_{\mathrm{m}}}{\sigma_{\mathrm{B}}}\right)^{\gamma}=1
$$

ただし， $\gamma$ は材料定数である. 式（8）のCFL 線図は，高温下でのセラミックスの疲労強度に及ぼす $R$ 依存性を 説明することができ， $\gamma$ は温度に依存することが実験的に認められている(21).

\section{$2 \cdot 2$ 統一的 PDF モデル}

負荷応力 $\sigma(t)$ 下でのセラミックス中の初期き裂からの SCG 挙動は Evans\&Fuller ${ }^{(5)}$ によって確立された破壊力学 モデルに基づいて定式化されている．長さ $a$ のき裂の $K_{\mathrm{I}}$ は

$$
K_{\mathrm{I}}=Y \sigma(t) \sqrt{a}
$$

と与えられる．ここで，Yはき裂の形状に依存する定数である. SCG 則はき裂進展速度（SCG 速度） $v$ と $K_{\mathrm{I}}$ の 関係として

$$
v=\frac{d a}{d t}=C\left(\frac{K_{\mathrm{I}}}{K_{\mathrm{IC}}}\right)^{n}
$$

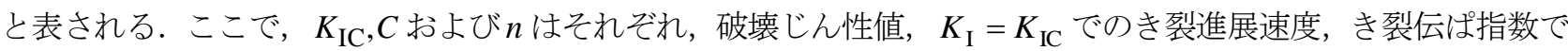
ある. 次に, 多数の初期き裂を伴う体積 $V$ のセラミックスが一つのき裂を含む複数の要素に分割でき, 各々の要 素において負荷応力は一定であると仮定する.このとき，式 (9) を用いて $a_{\mathrm{i}}$ から $a_{\mathrm{j}}$ まで式（10）を積分すれば,

$$
C \lambda \alpha^{n} \sigma_{\max , \mathrm{k}}{ }^{n} t_{\mathrm{eff}}=a_{\mathrm{i}}^{-\lambda}-a_{\mathrm{j}}^{-\lambda}
$$

を得る.ここで, $a_{\mathrm{i}}, a_{\mathrm{j}}$ および $\sigma_{\mathrm{max}, \mathrm{k}}$ はそれぞれ, 要素 $\mathrm{k}$ 中の初期き裂長さ, 時間 $\tau$ 後のき裂長さ, 要素 $\mathrm{k} に$ 作用している最大主応力であり, $\lambda=(n-2) / 2, \alpha=Y / K_{\mathrm{IC}}$ である. 一方,

$$
t_{\mathrm{eff}}=\int_{0}^{\tau}\left(\frac{\sigma_{\mathrm{k}}(t)}{\sigma_{\max , \mathrm{k}}}\right)^{n} d t
$$

は有効負荷時間である. セラミックスの $n$ 值は 1 より十分大きいため, 時間 $t_{\mathrm{eff}} N_{\mathrm{f}} \quad\left(a_{\mathrm{f}}\right.$ : 臨界き裂長さ）で不安 定成長が起こるとき，式（11）は

$$
C \lambda \alpha^{n} \sigma_{\text {max }, \mathrm{k}}^{n} t_{\mathrm{eff}} N_{\mathrm{f}}=a_{\mathrm{i}}^{-\lambda}
$$

と近似できる． $a_{\mathrm{i}}$ は $K_{\mathrm{IC}}$ と要素 $\mathrm{k}$ の不活性強度 $S_{\mathrm{i}}$ を用いて 


$$
a_{\mathrm{i}}=\left(\frac{K_{\mathrm{IC}}}{Y S_{\mathrm{i}}}\right)^{2}
$$

と表わされる．式（13）に式（14）を代入すると，要素 $\mathrm{k}$ の不活性強度 $S_{\mathrm{i}}^{*}$ が

$$
S_{\mathrm{i}}^{*}=\left(C \lambda \alpha^{2} \sigma_{\mathrm{max}, \mathrm{k}}{ }^{n} t_{\mathrm{eff}} N_{\mathrm{f}}\right)^{1 / 2 \lambda}
$$

と表される.いま， $S_{\mathrm{i}}$ が 2 母数ワイブル分布に従うとき，その要素 $\mathrm{k}$ の非破壊確率 $P_{\mathrm{k}}$ は

$$
P_{\mathrm{k}}=\exp \left[-\left(\frac{S_{\mathrm{i}}}{S_{\mathrm{o}}}\right)^{m}\right]
$$

と与えられる.ここで， $m$ および $S_{\mathrm{o}}$ はそれぞれ形状母数と尺度母数である. 式 (16) の $S_{\mathrm{i}}$ に式 (15) の $S_{\mathrm{i}}^{*}$ を代 入することにより， $P_{\mathrm{k}}$ が $\sigma_{\mathrm{max}, \mathrm{k}}$ と $t_{\mathrm{eff}} N_{\mathrm{f}}$ の関数として

$$
P_{\mathrm{k}}=\exp \left[-\left(\frac{C \lambda \alpha^{2} \sigma_{\mathrm{max}, \mathrm{k}}^{n} t_{\mathrm{eff}} N_{\mathrm{f}}}{S_{\mathrm{o}}^{2 \lambda}}\right)^{m / 2 \lambda}\right]
$$

と表わされる．ここで最弱リンクモデル説を適用すると，セラミックス全体（体積 $V ）$ の非破壊確率 $P$ は,

$$
P=\Pi P_{\mathrm{k}}=\exp \left[-\int_{V}\left(\frac{C \lambda \alpha^{2} \sigma_{\mathrm{max}, \mathrm{k}}^{n} t_{\mathrm{eff}} N_{\mathrm{f}}}{S_{\mathrm{o}}^{2 \lambda}}\right)^{m / 2 \lambda} d V\right]
$$

と表わされる. $\sigma_{\max , \mathrm{k}}$ が各々の要素に作用される応力の最大值 $\sigma_{\mathrm{max}}$ と対応寸るとき, 式 (12) から計算される $t_{\mathrm{eff}}$ はすべての要素に対して同じである.このとき式（18）は,

$$
P=\exp \left[-\left(\frac{\sigma_{\mathrm{max}}\left\{t_{\mathrm{eff}} N_{\mathrm{f}}\right\}^{1 / n}}{S_{\mathrm{o}} t_{\mathrm{o}}^{1 / n}}\right)^{m n / 2 \lambda} \int_{V}\left(\frac{\sigma_{\mathrm{max}, \mathrm{k}}}{\sigma_{\max }}\right)^{m n / 2 \lambda} d V\right]
$$

と書きかえられる. ただし分母を分子の変数の形と対応させるために, $S_{0} t_{0}^{1 / n}\left(t_{0}=K_{\mathrm{IC}}{ }^{2} / C \lambda\left(Y S_{\mathrm{o}}\right)^{2}\right)$ と書きか えた．セラミックスの $n$ 值は，一般的に 20 から 100 の範囲にあるので， $m n / 2 \lambda$ は $m$ 值とほぼ等しい. したがっ て, セラミックス全体の破壊確率 $F$ は, 式 (19) から

$$
F=1-\exp \left[-\left(\frac{\sigma_{\mathrm{max}}\left\{t_{\mathrm{eff}} N_{\mathrm{f}}\right\}^{1 / n} V_{\mathrm{eff}}^{1 / m}}{\hat{\sigma}_{\mathrm{o}}}\right)^{m}\right]
$$

と表わされる.ここで,

$$
V_{\text {eff }}=\int_{V}\left(\frac{\sigma_{\max , \mathrm{k}}}{\sigma_{\max }}\right)^{m} d V
$$

は有効体積であり， 


$$
\tilde{\sigma}_{\mathrm{f}}=\sigma_{\mathrm{max}}\left\{t_{\mathrm{eff}} N_{\mathrm{f}}\right\}^{1 / n} V_{\mathrm{eff}}^{1 / m}
$$

は $t_{\mathrm{eff}} N_{\mathrm{f}}=1 \mathrm{~s}$ および $V_{\mathrm{eff}}=1 \mathrm{~mm}^{3}$ で基準化された強度である. 式（20）の $m$ と $\hat{\sigma}_{\mathrm{o}}$ は $\tilde{\sigma}_{\mathrm{f}}$ で表された 2 母数ワイブル 分布の形状母数および尺度母数である. 3 つの統一的強度定数 $m, \hat{\sigma}_{0}$ および $n$ は, 様々な破壊試験から得られたセ ラミックスの実験データを用いて式（20）に基づくワイブル統計解析によって評価できる．最終的に，PDF モデ ルにおける統一的遅れ破壊式は

$$
\sigma_{\text {max }}\left\{t_{\text {eff }} N_{\mathrm{f}}\right\}^{1 / n}=\hat{\sigma}_{\mathrm{o}} \sqrt[m]{-\frac{\ln (1-F)}{V_{\text {eff }}}}
$$

と表わされる. 式 (23) は Okabe ${ }^{(17)(18)}$ によって提唱された統一的強さ評価法と一致する. 先に述べたように $n$ 值 は, 1 より十分に大きいため, $t_{\mathrm{eff}}$ は $\sigma_{\max }$ が作用している時間とほぼ等しい. よって本モデルでは，セラミック スの疲労 SCG が, 最大応力作用時にき裂が進展するという「完全時間依存型の遅れ破壊」であると仮定している. 式 $(23)$ から， $V_{\text {eff }}$ を有するセラミックスに対する $\sigma_{\text {max }}-t_{\mathrm{eff}}$ 線図, S- $\dot{\sigma}$ 線図, S-N 線図, S-t 線図を確率論的に 予測することができる.

\section{$2 \cdot 3$ 確率論的 CFL 線図}

$t_{\mathrm{eff}} N_{\mathrm{f}}, V_{\mathrm{eff}}, F$ に対する破壊強度 $\sigma_{\text {max }}^{*}$ は式 (23) から

$$
\sigma_{\text {max }}^{*}\left(t_{\text {eff }} N_{\mathrm{f}}, V_{\text {eff }}, F\right)=\hat{\sigma}_{\mathrm{o}}\left\{t_{\mathrm{eff}} N_{\mathrm{f}}\right\}^{-1 / n} V_{\mathrm{eff}} \sqrt[-1 / m]{m} \sqrt{-\ln (1-F)}
$$

と表される. 式 (2) で示した $\sigma_{\mathrm{a}}$ と $\sigma_{\mathrm{m}}$ の $\sigma_{\mathrm{max}}$ を式 (24) の $\sigma_{\mathrm{max}}^{*}\left(t_{\mathrm{eff}} N_{\mathrm{f}}, V_{\mathrm{eff}}, F\right)$ に置き換えることにより， $\sigma_{\mathrm{a}}$ と 自はそれぞれ

$$
\begin{aligned}
& \sigma_{\mathrm{a}}=\frac{1-R}{2} \sigma_{\text {max }}^{*}\left(t_{\mathrm{eff}} N_{\mathrm{f}}, V_{\mathrm{eff}}, F\right) \\
& \sigma_{\mathrm{m}}=\frac{1+R}{2} \sigma_{\text {max }}^{*}\left(t_{\mathrm{eff}} N_{\mathrm{f}}, V_{\mathrm{eff}}, F\right)
\end{aligned}
$$

と表される. 式 $(25)$ の $\sigma_{\mathrm{a}}$ を計算すれば, 任意の $t_{\mathrm{eff}}, V_{\mathrm{eff}}, F$ および $R$ に対する確率論的 S-N 線図が得られる. さらに式（25）から一定の $t_{\mathrm{eff}}, V_{\mathrm{eff}}$ および $F$ に対する確率論的 CFL 線図が次式のように得られる：

$$
\frac{\sigma_{\mathrm{a}}}{\sigma_{\text {max }}^{*}\left(t_{\mathrm{eff}} N_{\mathrm{f}}, V_{\mathrm{eff}}, F\right)}+\frac{\sigma_{\mathrm{m}}}{\sigma_{\text {max }}^{*}\left(t_{\mathrm{eff}} N_{\mathrm{f}}, V_{\mathrm{eff}}, F\right)}=1
$$

ここで，Fと $t_{\mathrm{eff}} N_{\mathrm{f}}$ および $V_{\mathrm{eff}}$ がそれぞれ $63.2 \% ， 1 \mathrm{~s}$ および $1 \mathrm{~mm}^{3}$ であるとき， $\sigma_{\mathrm{a}}$ と $\sigma_{\mathrm{m}}$ の関係は

$$
\frac{\sigma_{\mathrm{a}}}{\hat{\sigma}_{\mathrm{o}}}+\frac{\sigma_{\mathrm{m}}}{\hat{\sigma}_{\mathrm{o}}}=1
$$

となる. 式（27）は式（4）の修正 Goodman 線図の $\sigma_{\mathrm{a}} / \sigma_{\mathrm{w}}$ と $\sigma_{\mathrm{m}} / \sigma_{\mathrm{B}}$ を $\sigma_{\mathrm{a}} / \hat{\sigma}_{\mathrm{o}}$ と $\sigma_{\mathrm{m}} / \hat{\sigma}_{\mathrm{o}}$ に置き換えたものに等 しい.このように，確率論的 CFL 線図は修正 Goodman 線図と関係づけられる.

\section{3. モデルの検証}

\section{$3 \cdot 1$ 回転曲げを受ける $\mathrm{Si}_{3} \mathrm{~N}_{4}$ の疲労}

モデルの妥当性を検証するために, $R=-1$ および 0 の正弦波, $50 \mathrm{~Hz}$ の周波数, 大気中室温下で回転曲げを受 けた $\mathrm{Si}_{3} \mathrm{~N}_{4}\left(\mathrm{Y}_{2} \mathrm{O}_{3}-\mathrm{MgAl}_{2} \mathrm{O}_{4}\right.$ を焼結助剤とした常圧焼結チッ化ケイ素) の実験データを用いる(24)(25). 図 1 に $\sigma_{\max }$ と 


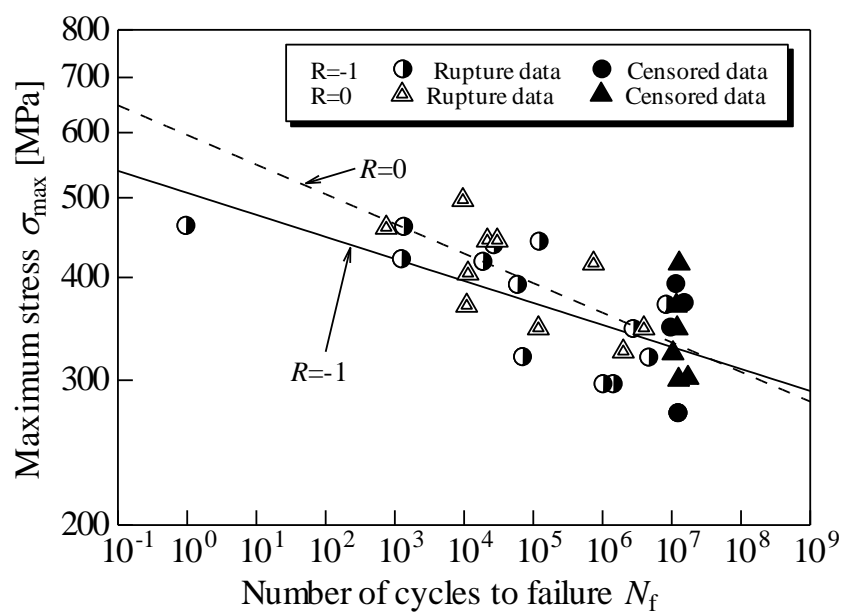

Fig.1 $\sigma_{\max }-N_{\mathrm{f}}$ plots ${ }^{(24)(25)}$.

$N_{\mathrm{f}}$ の関係を示す， $\sigma_{\max }$ は $N_{\mathrm{f}}$ の増加に伴い顕著に減少している. $R=-1$ での $\sigma_{\max }$ は, $R=0$ での $\sigma_{\max }$ より若 干低いことが認められた。この $R$ 依存性の原因として，有効体積と圧縮応力によるき裂閉口挙動の影響が考えら れる．前者は式（21）に示寸ように発生する応力分布に対する体積積分で計算され，值が大きいほど強度は低く なる．後者については，予き裂を導入した $\mathrm{Si}_{3} \mathrm{~N}_{4}$ の引張圧縮下でのき裂伝ぱ試験から，き裂閉口効果によりき裂 進展は加速される(26) と報告されている. Saruki ら ${ }^{(24)}$ は図 1 に示した $R$ 依存性について, これらの影響を議論した 結果，有効体積の影響による可能性が大きく，疲労強度は主に最大応力に依存すると結論付けている．ただし $R=-1$ での SCG 疲労はき裂閉口効果が全くないとは言えないことに注意を要する.

一般に，様々な破壊試験後のセラミックスの破面にはミラー，ミスト，ハックルと呼ばれる特徴のある脆性破 面が観察される． $\mathrm{Ko}^{(27)}$ は室温にて $\mathrm{Si}_{3} \mathrm{~N}_{4}$ の回転曲げ疲労試験を行い， $R$ によらずミラー領域に類似した破面を観 察している. したがって回転曲げを受ける $\mathrm{Si}_{3} \mathrm{~N}_{4}$ の疲労破壊は，潜在する初期き裂からの SCG によって起こり， その寿命のばらつきは初期き裂のばらつきに支配されると考えられる.

\section{$3 \cdot 2$ 統一的遅れ破壊解析}

図 2 にPDF モデルに基づく統一的強度定数を決定するためのフローチャートを示す. 先に述べた実験データを 用いて，PDF モデルに基づく解析から統一的強度定数を以下のように決定した.

式（23）において, $F=63.2 \%$ のとき, $V_{\mathrm{eff}}=1 \mathrm{~mm}^{3}$ で基準化された強度 $\tilde{D}_{\max }$ と $t_{\mathrm{eff}} N_{\mathrm{f}}$ の関係として

$$
\frac{t_{\mathrm{eff}} N_{\mathrm{f}}}{t_{\mathrm{o}}}=\left(\frac{\tilde{D}_{\mathrm{max}}}{S_{\mathrm{o}}}\right)^{-n}
$$

が与えられる.ここで $\widetilde{D}_{\max }$ は

$$
\tilde{D}_{\max }=\sigma_{\max } V_{\text {eff }}^{1 / m}
$$

である．また周波数 $f$ の正弦波での 1 サイクルあたりの $t_{\mathrm{eff}}$ は式（12）より

$$
t_{\mathrm{eff}}=\int_{0}^{\tau_{\mathrm{o}}}\left(\frac{1+R}{2}+\frac{1-R}{2} \sin \left[2 \pi \frac{\tau}{\tau_{\mathrm{o}}}\right]\right)^{n} d t
$$

ここで $\tau_{\mathrm{o}}=1 / f$ である. 次に $V_{\mathrm{eff}}$ は, Saruki ${ }^{(28)}$ の説を採用して, 図 3 の斜線部を回転曲げの有効体積とした。 こ こで $2 l_{0}$ と $2 l_{1}$ は, 平行部長さおよび断面係数 $z_{1}=z_{0}(1+\alpha / 100)\left(z_{0}\right.$ と $\alpha$ はそれぞれ平行部での断面係数と断面係 

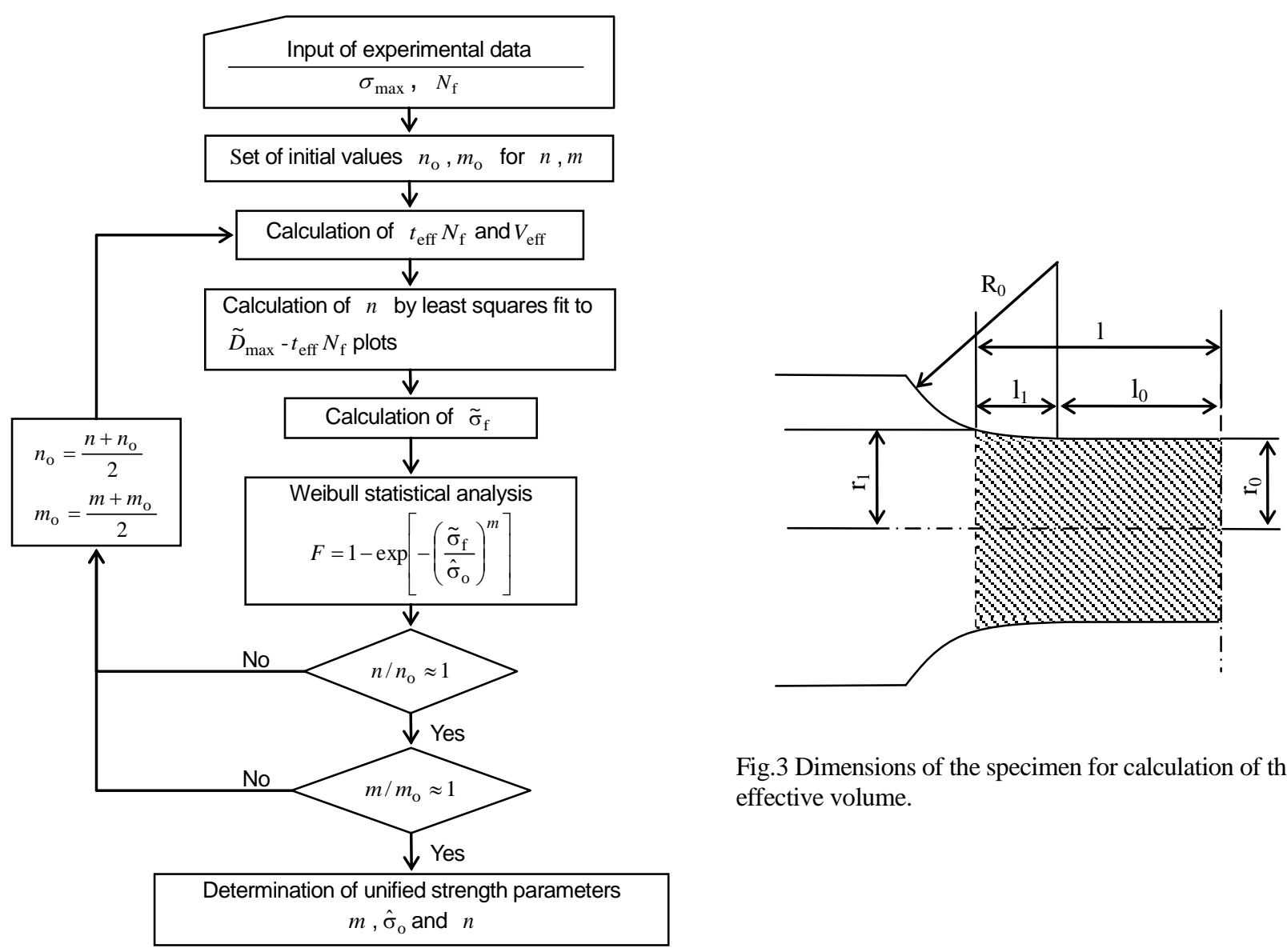

Fig.3 Dimensions of the specimen for calculation of the effective volume.

Fig.2 Flowchart for determination of unified strength parameters associated with the PDF model.

数比 $\left.z_{0} / z_{1}\right)$ での軸方向長さである. これより $R=0$ での $V_{\mathrm{eff}, \mathrm{R}}$ は式（21）において $\sigma_{\mathrm{max}, \mathrm{k}}$ を発生する応力 $\sigma に$ 置き換えて，次のように計算される：

$$
\begin{gathered}
\quad V_{\mathrm{eff}, \mathrm{R}}=\int_{V}\left(\frac{\sigma}{\sigma_{\mathrm{max}}}\right)^{m} d V=2\left(l_{0}+l_{1}\right) \int_{0}^{r_{0}}\left(\frac{r}{r_{0}}\right)^{m} 2 \pi r d r=2\left(l_{0}+l_{1}\right) 2 \pi r_{0}^{2} /(m+2) \\
\text { ここで } l_{1} \text { は } \\
l_{1}=\sqrt{{R_{0}{ }^{2}-\left\{R_{0}-\left(r_{1}-r_{0}\right)\right\}^{2}}^{2}}=\sqrt{\left(r_{1}-r_{0}\right)\left(2 R_{0}-r_{1}+r_{0}\right)}
\end{gathered}
$$

であり, 半径 $r_{1}$ は

$$
r_{1}=r_{0} \sqrt[3]{1+\frac{\alpha}{100}}
$$

である.一方， $R=-1$ での有効体積 $V_{\mathrm{eff}, \mathrm{Q}}$ は $2 V_{\mathrm{eff}, \mathrm{R}}$ で与えられる ${ }^{(24)}$. 今回, Saruki らの実験結果 ${ }^{(24)(28)}$ に基づき, $\alpha=10 \%$ とした.

初めに, 両対数グラフ上にプロットした $\tilde{D}_{\mathrm{max}}-t_{\mathrm{eff}} N_{\mathrm{f}}$ 線図の破断データのみに対する最小二乗法による近似曲 線の傾きから $n$ を決定した. 次に最小二乗法を用いて $t_{\mathrm{eff}} N_{\mathrm{f}}=1 \mathrm{~s}$ および $V_{\mathrm{eff}}=1 \mathrm{~mm}^{3}$ に対する $\tilde{\sigma}_{\mathrm{f}}$ のワイブルプロ ット中の破断データに対する統計解析から $m$ および $\hat{\sigma}_{\mathrm{o}}$ を決定した。 このとき $F$ はメディアンランク法によって 


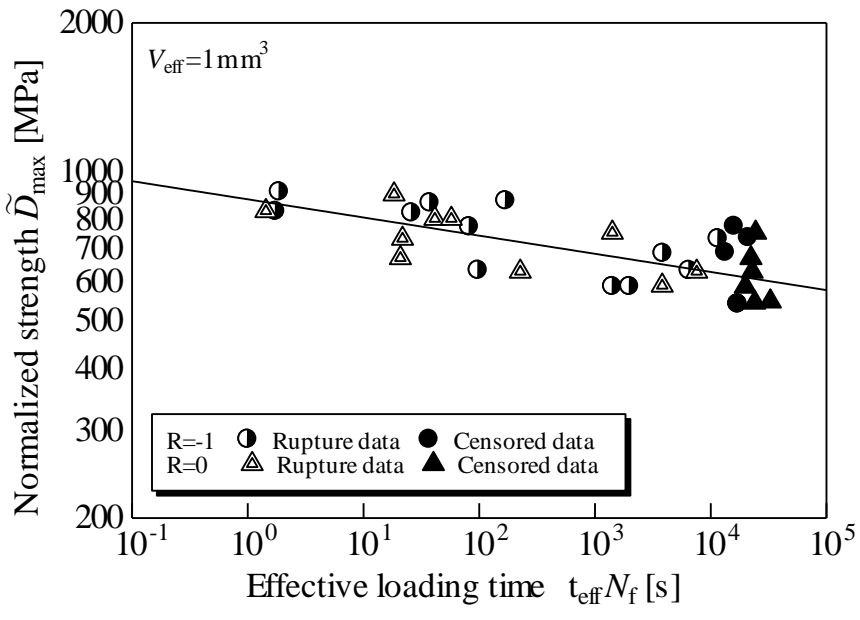

Fig.4 $\tilde{D}_{\text {max }}-t_{\text {eff }} N_{\text {eff }}$ plots.

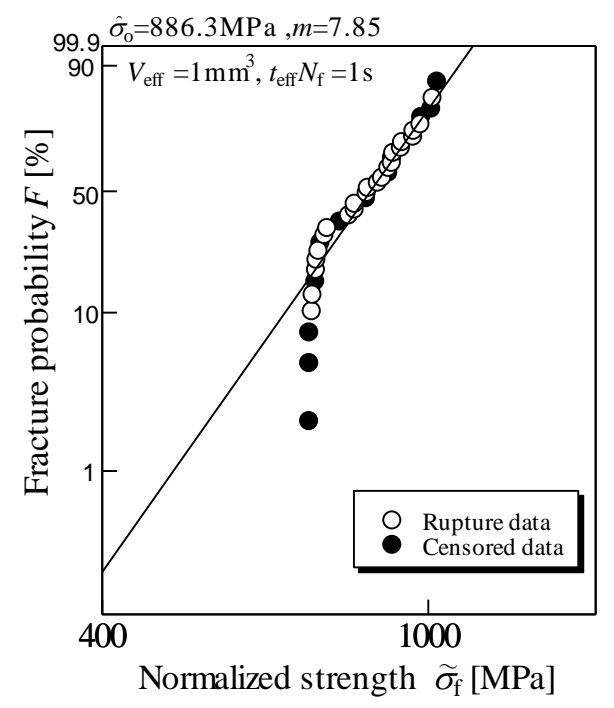

Fig.5 Weibull plots of normalized strength.

評価した. これら推定を図 2 に示すように $m / m_{\mathrm{o}}$ と $n / n_{\mathrm{o}}$ がほぼ 1 に収束するまで繰り返し， 3 つの統一的強度定 数 $m, \hat{\sigma}_{\mathrm{o}}$ および $n$ を評価した.

図 4 に $\widetilde{D}_{\max }-t_{\mathrm{eff}} N_{\mathrm{f}}$ プロットと近似曲線を示す。この結果は，回転曲げを受ける $\mathrm{Si}_{3} \mathrm{~N}_{4}$ の疲労破壊が，「完全時 間依存型の遅れ破壊」に従い, 疲労強度の $R$ 依存性は 3.1 節で述べたように有効体積および最大応力に依存する ことを示唆するものである. これより， $n=34.6$ が得られた．次に，図 5 に $\tilde{\sigma}_{\mathrm{f}}$ のワイブルプロットを示す. この 結果より, $m=7.85, \hat{\sigma}_{0}=886.3 \mathrm{MPa}$ が得られた. 図 5 にこれを用いて式（20）に基づき計算した 2 母数ワイブ ル線図を実線として示寸，ワイブルプロットと 2 母数ワイブル線図はおおおよそ従っているが，およそ $F=30 \%$ 以 下の領域では，ある下限值（約 600〜 700MPa）が存在する.このような挙動を表現するには位置パラメータを含 む 3 母数ワイブル分布 ${ }^{(17)}$ を適用する必要がある.

\section{$3 \cdot 3$ 確率論的 S-N 線図および CFL 線図の予測}

図 6 に実験データの $\sigma_{\mathrm{a}}-N_{\mathrm{f}}$ プロットと統一的強度定数を用いて式（25）から予測した $F=20 \%, 63.2 \%$ おび 90\%，R=-1 および 0 に対する S-N 線図を示す．予測值は実験值のばらつきを含めて疲労強度低下の傾向をよく 再現できている. 一定 $R$ での S-N 線図で比較した場合, $F$ が小さいほじ同じ応力振幅に対して寿命は短い. また, 一定 $F$ での S-N 線図で比較した場合, 最大応力が高いため, $R$ が大きいほど同じ応力振幅に対して寿命は短くな る.

図 7 に $F=20 \%, 63.2 \%$ おび $90 \%$ におる各 $V_{\mathrm{eff}}$ および $t_{\mathrm{eff}} N_{\mathrm{f}}$ に対する確率論的 CFL 線図と実験データのプロ ットを示す，予測值は，実験值とよく一致しており，疲労強度の $R$ 依存性および $N_{\mathrm{f}}$ の影響を考慮した CFL 線図 をよく再現できている。一定 $F$ における CFL 線図で比較した場合, $t_{\mathrm{eff}} N_{\mathrm{f}}$ が長いほど, または $V_{\mathrm{eff}}$ が大きいほど 左側にシフトし，より安全側の予測を与えている．また，一定の $t_{\mathrm{eff}} N_{\mathrm{f}}$ および $V_{\mathrm{eff}}$ での CFL 線図において， $F$ が 小さいほどより安全側にある.

\section{4. 結}

本論文では，SCG 則と不活性強度の 2 母数ワイブル分布を組み合わせた確率論的 PDF モデルを用いて確率論 的 CFL 線図を提案し，その CFL 線図から，修正 Goodman 線図を導いた．次に回転曲げを受ける $\mathrm{Si}_{3} \mathrm{~N}_{4}$ の実験デ 一タから決定された PDF モデルに基づく統一的強度定数を用いて確率論的 CFL 線図を予測した．予測線図は実 験值とよく一致しており，本モデルの妥当性が確認された．本モデルは許容される破壊確率や，有効体積および 有効負荷時間に対する $\sigma_{\mathrm{a}}-\sigma_{\mathrm{m}}$ 線図を与えるため, 構造設計を行う際に有効である. 


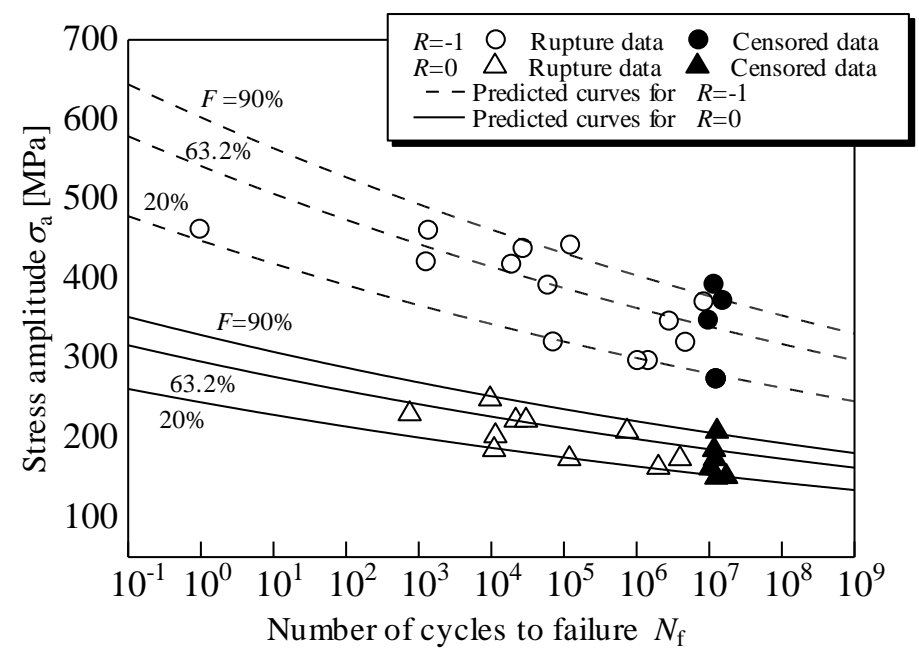

Fig.6 Measured and predicted $\sigma_{\mathrm{a}}-N_{\mathrm{f}}$ curves.
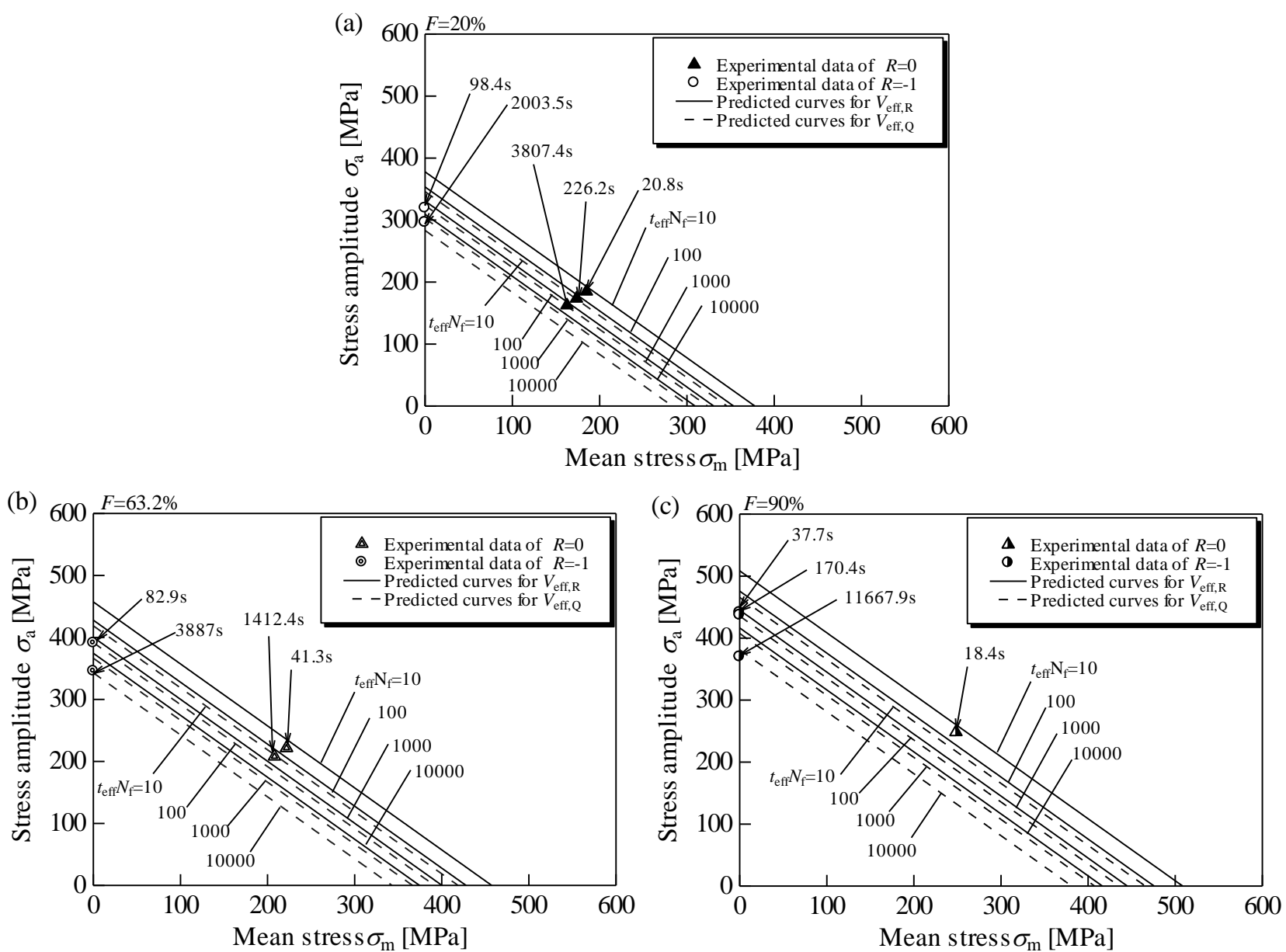

Fig.7 Probabilistic CFL diagrams for various values of effective volume $V_{\mathrm{eff}}$ and effective loading time $t_{\mathrm{eff}} N_{\mathrm{f}}$ at fracture probability $F$ of (a) $20 \%$, (b) $63.2 \%$ and (c) $90 \%$.

\section{文献}

(1) Takahashi, M., Okabe, N., Abe, Y., Fujiki, K. and Kanbayashi, R., "Fracture analysis for ceramic ball in backflow value", Fatigue \& Fracture of Engineering Materials \& Structures, published online 20 (2011).

(2) Zhou, J.L., Wu, G.Q., Zhu, W.N. and Chen, X.Y., "Tensile stress fatigue life model of silicon nitride ceramic balls", Tribology international, Vol.42, Issues 11-12 (2009), pp.1838-1845. 
(3) Suyama, S., Kameda, T. and Itoh, Y., "Development of high-strength reaction-sintered silicon carbide", Diamond and related Materials Vol.12, Issues 3-7 (2003), pp.1201-1204.

（4）伊藤義康，須山章子，“高強度反応焼結炭化厅イ素の微構造評価”，材料，Vol.57, No.3 (2008), pp.304-309.

(5) Evans, A.G. and Fuller, E.R., "Crack propagation in ceramic materials under cyclic loading conditions”, Metallurgical and Materials Transactions-B, Vol.5, No.1 (1974), pp.27-33.

(6) Evans A.G. and Wiederhorn, S.M., "Proof testing of ceramic materials -an analytical basis for failure prediction", International Journal of fracture, Vol.10, No.3 (1974), pp.379-392.

(7) Evans A.G. and Fuller, E.R., "Proof testing -the effects of slow crack growth", Materials Science and Engineering, Vol.19, Issue 1 (1975), pp.69-77.

(8) Evans, A.G. and Johnson, H., "The fracture stress and its dependence on slow crack growth", Journal of Materials Science, Vol.10, No.2 (1975), pp.214-222.

(9) Evans, A.G., "Fatigue of ceramics”, International Journal of Fracture, Vol.16, No.6 (1980), pp.485-498.

(10) Evans, A.G., "Slow crack growth in brittle materials under dynamic loading conditions", International Journal of Fracture, Vol.10, No.2 (1974), pp.251-259.

(11) Ritter, J.E. and Humenik, J.N., "Static and dynamic fatigue of polycrystalline alumina", Journal of Materials Science, Vol.14, No.3 (1979), pp.626-632.

(12) Ping, Z., Zhongqin, L., Guanlong, C. and Ikeda, K., "The predictions and applications of fatigue lifetime in alumina and zirconia ceramics", International Journal of Fatigue, Vol.26, Issue10 (2004), pp.1109-1114.

(13) Pan, L.S., Matsuzawa, M. and Horibe, S., "Stress rate dependence of fracture strength in pre-cracked zirconia ceramics", Materials Science and Engineering:A, Vol.244, Issue 2 (1998), pp.199-206.

(14) Jakus, K., Coyne, D.C. and Ritter Jr, J.E., “Analysis of fatigue data for lifetime predictions for ceramic materials”, Journal of Materials Science, Vol.13, No.10 (1978), pp.2071-2080.

(15) Seshadri, S.G., Srinivasan, M. and Weber, G.W., "Evaluation of slow crack growth parameters for silicon carbide ceramics", Journal of Materials Science, Vol.17, No.5 (1982), pp.1297-1302.

(16) Davidge, R.W., McLaren, J.R. and Tappin. G., "Strength-probability-time (SPT) relationships in ceramics", Journal of Materials Science, Vol.8, No.12 (1973), pp.1699-1705.

(17) 岡部永年, 平田英之, 村松正光, “セラミックス強度の統一的評価の信頼性設計への適用の検討”, 材料, Vol.39, No.439 (1990), pp.393-399.

(18) Okabe, N. and Ikeda, T., "Strength evaluation method and design optimization for ceramic gas turbine blades", Materials science and engineering:A, Vol.143, Issues 1-2 (1991), pp.11-19.

(19) Ritter, J.E., "Predicting lifetimes of materials and material structures", Dental Materials, Vol.11, Issue 2 (1995), pp142-146.

(20) Masuda, M., Soma, T., Masuda, M., Matsui, M. and Oda, I., "Cyclic fatigue testing of ceramic materials", International Journal of High Technology Ceramics, Vol.4, Issues2-4 (1988), pp.289-299.

(21) Masuda, M., Soma, T. and Matsui, M., "Cyclic fatigue behavior of $\mathrm{Si}_{3} \mathrm{~N}_{4}$ ceramics", Journal of the European Ceramic Society, Vol.6, Issue 4 (1990), pp.253-258.

（22）栘田昌明，相馬隆男，松井實，小田功，“セラミックスの疲労（第 1 報）一引張-圧縮繰り返し応力下における常圧 焼結窒化ケイ素の疲労挙動—”，日本セラミックス協会学術論文誌，Vol. 96, Issue 3 (1988), pp.277-283.

(23) Marin, J., "Interpretation of fatigue strength for combined stresses", Proceedings of international conference fatigue metals, London (1956), pp.184-192.

(24) 猿木勝司, 山田明, “常圧焼結窒化ケイ素の常温におけるねじり疲労強度”, 日本機械学会論文集 A 編, Vol.55, No.515 (1989), pp.1507-1511.

(25) Nakazawa, H., CERAMICS STRENGTH DATABASE Vol.1, (1996), pp.178-180, Journal of the Society of Materials Science, Japan.

（26）岸本秀弘, 上野明, 河本洋, 藤井康義, “窒化ケイ素セラミックスの繰返し荷重下におけるき裂進展挙動一荷重波 形および圧縮荷重の影響—”，材料，Vol.38, No.433 (1989), pp.1212-1217. 
(27) Ko, H.N., "Behavior of Mirror-like Region of Sintered Si3N4 under Rotary Bending and Static Fatigue", Journal of the Ceramic Society of Japan, Vol.99, No.7 (1991), pp.533-537.

(28) 猿木勝司, 小川一義, 浅野高司, “常圧窒化ケイ素の常温における曲げ疲労強度”, 日本機械学会論文集A編, Vol.54, No.508 (1988), pp.2082-2086. 